\title{
Genetic Evaluation of ALADIN Gene in Early-Onset Achalasia and Alacrima Patients
}

\author{
Kee Wook Jung, ${ }^{1}$ In Ja Yoon, ${ }^{1}$ Do Hoon Kim, ${ }^{1}$ Jun-Won Chung, ${ }^{1}$ Kwi-Sook Choi, ${ }^{1}$ Kee Don Choi, ${ }^{1}$ Ho June Song, ${ }^{1}$ \\ Gin Hyug Lee, ${ }^{1}$ Seung-Jae Myung, ${ }^{1}$ Jin-Ho Kim, ${ }^{1}$ Dhiraj Maskey, ${ }^{2}$ Myeung Ju Kim ${ }^{2}$ and Hwoon-Yong Jung ${ }^{1 *}$ \\ ${ }^{1}$ Asan Digestive Disease Research Institute, Department of Internal Medicine, Asan Medical Center, University of Ulsan College of Medicine, \\ Seoul, Korea, ${ }^{2}$ Department of Anatomy, College of Medicine, Dankook University, Cheonan, Korea
}

\section{Background/Aims}

ALADIN gene has been known to cause achalasia, alacrima, adrenal abnormalities and a progressive neurological syndrome. A considerable proportion of achalasia patients has been known to show alacrima (decreased secretion of tear). However, the genetic mechanism between achalasia and alacrima has not been defined yet. We postulated that ALADIN gene may be involved in the occurrence of early-onset achalasia; thus, we investigated the correlation of ALADIN gene in early-onset achalasia patients.

\section{Methods}

From 1989 to 2007, patients who were diagnosed as primary achalasia before age 35 were enrolled. All of the enrolled patients were asked for (1) blood sampling for DNA, (2) Shirmer test and (3) dysphagia questionnaires.

\section{Results}

The ALADIN gene in exon 1, 2, 10, 11 and 12 from 19 patients was investigated (M:F = 12:7). The mean age of patients at diagnosis was $27 \pm 5(15-35)$ years old. Eight out of $19(42 \%)$ showed alacrima by the positive Shirmer test. In spite of thorough exam in the genetic study, there was no definite abnormal genetic finding in this study.

\section{Conclusions}

A considerable number of achalasia patients showed alacrima. Due to the limitation of this study, it is difficult to conclude that early-onset achalasia may have significant correlations with the ALADIN gene.

\section{(J Neurogastroenterol Motil 2011;17:169-173)}

Key Words

AAAS protein; Esophageal achalasia; Human; Shirmer test

Received: October 15, 2010 Revised: February 9, 2011 Accepted: February 18, 2011

(c) This is an Open Access article distributed under the terms of the Creative Commons Attribution Non-Commercial License (http://creativecommons. org/licenses/by-nc/3.0) which permits unrestricted non-commercial use, distribution, and reproduction in any medium, provided the original work is properly cited.

*Correspondence: Hwoon-Yong Jung, MD

Asan Digestive Disease Research Institute, Department of Internal Medicine, Asan Medical Center, University of Ulsan College of Medicine, 388-1 Pungnap 2-dong, Songpa-gu, Seoul, Korea

Tel: +82-2-3010-3197, Fax: +82-2-476-0824, E-mail: hyjung@amc.seoul.kr

Financial support: This study was supported by a grant (No. 2008-261) from the Korean Society of Neurogastroenterology and Motility, Seoul, Korea. Conflicts of interest: None. 


\section{Introduction}

Achalasia has been known to be an inflammatory disease of unknown etiology characterized by esophageal aperistalsis and failure of lower esophageal sphincter (LES) relaxation due to loss of inhibitory nitrinergic neurons in the esophageal myenteric plexus. ${ }^{1}$ Its pathophysiology has not been fully evaluated. However, infectious causes including Chagas' disease and autoimmune causes such as circulating autoantibodies against the myenteric plexus were suggested as the major culprits of achalasia. ${ }^{1-4}$ Triple A (Allgrove) syndrome has been characterized by achalasia, alacrima, and adrenocorticotrophic hormone (ACTH) resistant adrenal insufficiency. ${ }^{5}$ This is a rare genetic disorder, with autosomal recessive inheritance, caused by genetic mutations on chromosome 12q13 (ALADIN or AAAS gene). ${ }^{6}$ While a recent report showed that $20 \%$ of achalasia patients showed deficient secretion of tear, the relationship between the alacrima and achalasia has not been defined. ${ }^{7}$ Recently, young male patients who exhibited achlasia and alacrima without other features of triple A syndrome were reported. ${ }^{8}$ We postulated that there might be genetic variation regarding triple A syndrome and considerable proportion of early-age onset achalasia might have correlation with ALADIN gene. We aimed to investigate the relationship between early-age onset achalasia and ALADIN gene.

\section{Materials and Methods}

From 1989 to 2007, all of achalasia patients who were diagnosed as primary achalasia before age 35 in Asan Medical Center was asked to enroll this genetic study. By the review of medical record, a total of 44 patients was indicated to this study. A letter containing the detailed protocol and request for the participation in the study was sent to the patients. A total of 19 patients of primary achalasia answered the mail and allowed to enroll in this study. Finally a total of 19 patients (M:F = 12:7) of primary achalasia were enrolled. The mean age of patients at diagnosis was $27 \pm 5$ (15-35) years old. Most of them exhibited classic achalasia pattern by esophageal manometry, except for three patients showing vigorous achalasia pattern. All of them was explained with the aim and method of this study, and written consent forms were given. All of the enrolled patients was asked for (1) blood sampling for DNA, (2) Shirmer test and (3) dysphagia questionnaires. This study was approved by the IRB of Asan Medical Center. This allocations are depicted in Figure.

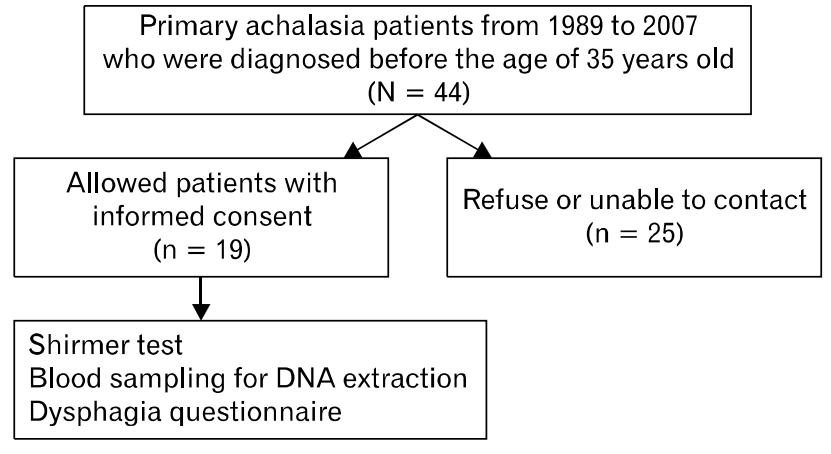

Figure. Depicted patients allocations.

\section{Blood Sampling for DNA}

We extracted genomic DNA from blood samples with informed consent and performed linkage studies using microsatellite DNA available from the Genethon genetic map and Genome Database. Extraction of DNA from patients was performed in two steps. First, DNA preparation was done from whole blood of each patient. White blood cell from whole blood was separated by erythrocyte lysis buffer. Genomic DNA from whole WBC was obtained using a genomic DNA purification kit (Wizard, Promega, Madison, WI, USA). The blood was stored at $4^{\circ} \mathrm{C}$. About 3-3.5 volume of EL buffer was added, mixed and chilled on ice for 20 minutes (RBC lysis). It was centrifuged at 2,000 rpm for 10 minutes. Supernatant was discarded and washed with EL buffer $(10 \mathrm{~mL})$. Later, it was re-centrifuged at 2,000 rpm for 10 minutes. Supernatant was discarded and suspended in $200 \mu \mathrm{L}$ phosphate buffered saline (PBS). Genomic DNA was extracted from whole WBC by following methods. $600 \mu \mathrm{L}$ of nucleic lysis solution was added to cell suspension, and then it was mixed gently by pipeting up and down three to five times to lyse the cells. The lysate was incubated at $65^{\circ} \mathrm{C}$ for 20 minutes. To the room temperature sample, $200 \mu \mathrm{L}$ of protein precipitation was added. Solution was vortex-mixed, followed by vigorous centrifugation at high speed for 20 seconds, and samples were chilled on ice for 5 minutes. Centrifugation was done for 5 minutes at $16,000 \times \mathrm{g}$. The supernatant containing genomic DNA was carefully removed and it was transferred to $1.5 \mathrm{~mL}$ tube containing $600 \mu \mathrm{L}$ of room-temperature isopropanol. The solution was gently mixed by inversion until the white thread-like strand of genomic DNA appeared. It was centrifuged for 1 minute at 16,000 $\times \mathrm{g}$. The supernatant was carefully decanted and $600 \mu \mathrm{L}$ of $70 \%$ ethanol was added at room temperature. It was centrifuged for 1 minute at $16,000 \times \mathrm{g}$. The pellet was dried at air for $10-15$ minutes. $100 \mu \mathrm{L}$ of DNA rehydration solution was added and 
DNA was rehydrated by incubating overnight at room temperature or $4^{\circ} \mathrm{C}$.

Polymerase chain reaction (PCR) was carried out in a total volume of $50 \mu \mathrm{L}$ contained $20 \mathrm{ng}$ of DNA, $0.2 \mathrm{mM}$ dNTPs, 1 $\mathrm{U}$ of Taq Gold polymerase, $1.5 \mathrm{mM} \mathrm{MgCl}$, $75 \mathrm{mM}$ Tris $\mathrm{HCl}$ (pH 9.0), $20 \mathrm{mM}\left(\mathrm{NH}_{4}\right)_{2} \mathrm{SO}_{4}, 0.01 \%$ Tween-20 and 50 pmol of each primer. PCR was performed on a Perkin-Elmer 9700 thermal cycler (Perkin Elmer, Applied Biosystems, Foster City, California, USA). The cycling consisted of denaturation at $94^{\circ} \mathrm{C}$ for 10 minutes, followed by 30 cycles of $94^{\circ} \mathrm{C}$ for 30 seconds, annealing temperature for 30 seconds, and $72^{\circ} \mathrm{C}$ for 35 seconds. Final extension at $72^{\circ} \mathrm{C}$ for 10 minutes was carried out, and it was stored at $4^{\circ} \mathrm{C}$. PCR fragments were checked on a $1 \%$ agarose gel. PCR fragments were checked on a $1 \%$ agarose gel. Primers used in this study were exon 1,2,10,11 and 12. The characteristics of each primer were described in Table 1 . The PCR products were purified by using a Qiaquick purification kit (Qiagen, Hilden, Germany) and resuspended in $50 \mathrm{~mL}$ of deionized water. For each exon, $100 \mathrm{ng}$ of amplified product was sequenced using forward and reverse primers and the BigDye Terminator cycle sequencing kit (Perkin Elmer). Sequencing was performed on an ABI377 automated sequencer. Alignment and analysis were carried out with Sequence Navigator (Perkin Elmer).

Table 1. Used Primer in DNA Test

\begin{tabular}{|c|c|c|c|}
\hline Exon & Sequence & Size & $\begin{array}{l}\text { Annealing } \\
\text { temperature }\end{array}$ \\
\hline EX-1 F & $\begin{array}{l}\text { 5'-GTC CGC ATA CGA ATC } \\
\text { TAG CCC-3' }\end{array}$ & $324 \mathrm{bp}$ & $57.6^{\circ} \mathrm{C}$ \\
\hline EX-1 R & $\begin{array}{l}\text { 5'-AGA CTC TGT GAC CCT } \\
\text { GCC CCT-3' }\end{array}$ & & $62.5^{\circ} \mathrm{C}$ \\
\hline EX-2 F & $\begin{array}{l}\text { 5'- ATC TCT TAT ACT TAG } \\
\text { CCC AGC-3' }\end{array}$ & $328 \mathrm{bp}$ & $51.3^{\circ} \mathrm{C}$ \\
\hline EX-2 R & $\begin{array}{l}\text { 5'-GAA TAA AAG TCT TTT } \\
\text { GAA GAA CAC-3' }\end{array}$ & & $48.8^{\circ} \mathrm{C}$ \\
\hline EX-10 F & $\begin{array}{l}\text { 5'-AGA AAG GCA CTT AGC } \\
\text { TCC TGG-3' }\end{array}$ & $259 \mathrm{bp}$ & $56.8^{\circ} \mathrm{C}$ \\
\hline $\mathrm{EX}-10 \mathrm{R}$ & $\begin{array}{l}\text { 5'-GAA TGC AGG AGG GAA } \\
\text { AGT AGA-3' }\end{array}$ & & $54.1^{\circ} \mathrm{C}$ \\
\hline $\mathrm{EX}-11 \mathrm{~F}$ & $\begin{array}{l}\text { 5'-CTC TAC TTT CCC TCC } \\
\text { TGC ATT CT-3' }\end{array}$ & $247 \mathrm{bp}$ & $56.1^{\circ} \mathrm{C}$ \\
\hline $\mathrm{EX}-11 \mathrm{R}$ & $\begin{array}{l}\text { 5'-TAT TTC CCT TTA TCC } \\
\text { CTC AGA GC-3' }\end{array}$ & & $54.0^{\circ} \mathrm{C}$ \\
\hline $\mathrm{EX}-12 \mathrm{~F}$ & $\begin{array}{l}\text { 5'-CAG CTC TGA GGG ATA } \\
\text { AAG GGA AA-3' }\end{array}$ & $297 \mathrm{bp}$ & $56.4^{\circ} \mathrm{C}$ \\
\hline $\mathrm{EX}-12 \mathrm{R}$ & $\begin{array}{l}\text { 5'-CAG GTT AGG AGA GTT } \\
\text { TCA GTG TGG-3' }\end{array}$ & & $57.0^{\circ} \mathrm{C}$ \\
\hline
\end{tabular}

\section{Shirmer Test}

The Shirmer I test was undergone in all of the enrolled patients. The Shirmer test without anesthesia (Shirmer I test) is known to be a well-standardized test that is currently performed with the patient's eyes closed. ${ }^{9,10}$ This is a test to estimate tear reflex by insertion of a filter paper $\left(5 \times 35 \mathrm{~mm}\right.$, Color Bar ${ }^{\mathrm{TM}}$, EagleVision Co, Memphis, TN, USA) into the conjunctival sac. All patients were asked not to take any medications which can affect the result of Shirmer test including anti-histamine, or common cold drugs containing anti-histamine or decongestants before 7 days of the Shirmer test. Achalasia patients with combined rheumatologic disorders which can affect the result of Shirmer test including Sjögren's disease were excluded. A Shirmer paper strip folded at $5 \mathrm{~mm}$ from one end was inserted over the lower lid margin, midway between the middle and outer third. The patient was asked to close eye. After 5 minutes, the interpretation of result was done. The cut-off value $<10 \mathrm{~mm}$ was determined as decreased secretion of tear. ${ }^{10}$ If the result of 1 eye was abnormal, the patient was regarded to have abnormally decreased secretion of tear.

\section{Dysphagia Questionnaire}

All of enrolled patients were asked with dysphagia questionnaire (Asan dysphagia questionnaire) regarding their symptoms associated with dysphagia. Questionnaires consisted of duration of dysphagia, the age of first diagnosis, family history of dysphagia and number of balloon dilatation.

\section{Statistical Methods}

The Mann-Whitney $U$ test was utilized due to the skewed and relatively small number of samples used to compare the numerical data. The chi-square test or the Fisher's exact test was used to analyze non-numerical data. A $P$-value $<0.050$ was regarded as statistically significant. All analyses were performed with SPSS 14.0 (SPSS Inc, Chicago, IL, USA) for Windows.

\section{Results}

\section{Shirmer Test}

Eight out of 19 (42\%) showed alacrima by the positive Shirmer test. Patients were categorized into positive and negative Shirmer test groups. The characteristics of each group were compared (Table 2). However, there were no significant differences 
Table 2. Results of the Shirmer Test in Early-Age Onset Achalasia

\begin{tabular}{|c|c|c|c|}
\hline Variables & $\begin{array}{c}\text { Alacrima } \\
(\mathrm{n}=8)\end{array}$ & $\begin{array}{c}\text { Normal } \\
\text { secretion } \\
\text { of tear }(n=11)\end{array}$ & $P$-value \\
\hline $\operatorname{Sex}(M: F)$ & $6: 2$ & $6: 5$ & 0.362 \\
\hline Age at first symptom ${ }^{a}$ & $28(23-35)$ & $28(13-30)$ & 0.679 \\
\hline Age at first diagnosis ${ }^{a}$ & $26(22-35)$ & $26(15-33)$ & 0.300 \\
\hline \multicolumn{4}{|l|}{ Shirmer test } \\
\hline Right eye $(\mathrm{mm})^{\mathrm{a}}$ & $4.0(0-8)$ & $25.0(10-35)$ & $<0.003$ \\
\hline Left eye $(\mathrm{mm})^{\mathrm{a}}$ & $6.5(0-8)$ & $25.0(12-35)$ & $<0.001$ \\
\hline Vigorous achalasia (n) & 1 & 2 & 0.738 \\
\hline Disease duration $(\mathrm{yr})^{\mathrm{a}}$ & $3(1-15)$ & $3(1-16)$ & 0.430 \\
\hline No. of balloon dilatation $^{a}$ & $1(0-3)$ & $1(1-2)$ & 0.957 \\
\hline Family history of dysphagia (n) & 1 & 1 & 0.811 \\
\hline
\end{tabular}

${ }^{\mathrm{a}}$ Data are presented as median (range).

between them except for the result of Shirmer test.

\section{DNA Analysis}

We investigated the ALADIN gene in exon 1, 2, 10, 11 and 12 from 19 patients $(M: F=12: 7)$. At first, the doubtful sequences, the majority of which were A insertions, were only found between 40th and 41st location in the exon 1 throughout the ALADIN gene among 4 out of 19 enrolled patients. For further confirmation of doubtful sequence, additional DNA sequence analyses were performed. However, the previously identified inserted A was not a real finding. For that reason, in this study, the genetic mutations were not considered to be present.

\section{Discussion}

Early-onset achalasia patients exhibited considerable proportion of alacrima. However, the reason of alacrima was uncertain by this study. The overlooking in the sample volume limit of consented patients as well as their number may cause to gain undesirable results since all designed primers had not been applied even. If volume and number of samples were prepared enough, more chances could be made to elucidate genetic alterations in the achalasia patients by using unused primers.

By our study, considerable proportion of early-onset achalasia patients (42\%) exhibited alacrima. In the study of Verma et $\mathrm{al}^{7} 4$ out of 20 achalasia patients $(20 \%)$ exhibited alacrima. Verma's study enrolled the achalasia patients of the age from 21 to 84 years old. However, our study just enrolled the early-age onset achalasia patients whose onset age was before 35 years old.
By this result, we postulated that younger achalasia patients might have more possibility of the genetic association with ALADIN gene.

The defect of AAAS gene might create the symptoms of alacrima, achalasia and adrenal insufficiency. However, late onset triple A syndrome only was reported as a case report in which only one or two of these manifestations were shown such as alacrima and achalasia without adrenal insufficiency. Therefore, we postulated that early onset achalasia patients could have enough reason that those symptoms were caused by AAAS genetic defect.

We tried to find the genetic association between ALADIN gene and achalasia with alacrima. However, the result was uncertain. We postulated that there might be 2 hypotheses. First, achalasia and alacrima of patients might have no correlation between them. Therefore, the etiology of achalasia and alacrima might be different from the beginning. Second, another genetic mechanism might reside in both achalalasia and alacrima. Due to limitation of the number of patients and budget, we could not evaluate the full sequence of enrolled patients. If more available patients could be analyzed in this study, we could find more valuable results from the achalasia patients.

We found the considerable proportion of early-age onset achalasia had alacrima. Alacrima could be manifested by the iatrogenic causes including anti-histamine medication. However, all of the enrolled patients refrained from the medications causing decreased secretion of tear. Connective tissue disorders including Sjögren's syndrome could manifest alacrima. However, all the enrolled patients were negative from the symptoms and signs of connective tissue disorders. When compared from the previous report of alacrima in $20 \%$ of achalasia patients from young to old age, our study based on the early-age onset achalasia with the onset age below 35 years old might have more proportion of alacrima. ${ }^{7}$ The mean age of patient taking Shirmer test was $32 \pm$ 6 years old. Of the relatively young achalasia patients, $42 \%$ showed decreased secretion of tear. Older patients usually show decreased secretion of tear or saliva due to degenerative change of secretory gland. The exact mechanism is not clear. If the ALADIN gene has no definite correlation with alacrima, further studies regarding the relationship between them might be needed.

We used the primers in exon 1,2,10, 11 and 12, which were selected by the reference of other group from 19 patients to investigate the mutations. ${ }^{11}$ According to the other group's physical map of the triple-A critical region, ${ }^{12}$ the disease genes were presumed to be confined in the chromosome $12 \mathrm{q} 13,{ }^{13,14}$ where 16 exons are included. Although present work does not show any 
mutations in 16 Korean patients, the possibility of genetic correlation should not be easily ignored since the number of patients in present work was not large and another possibility of mutation detection in other exons by using possible primers (supplementary data ${ }^{12}$ ) is still remained as well. Unfortunately, we could not find any definite Triple A syndrome patients with ACTH insensitivity by symptoms alone. Because of limitation of finance and difficulty in sampling regarding ACTH insensitivity, we could not gather sufficient data to define the relationship between ACTH insensitivity and our cohort patients. However, based on the previously published papers, ${ }^{8,15}$ those patients could show the ACTH insensitivity.

In conclusion, the considerable proportion of early-age onset achalasia manifested alacrima. The genetic association between these patients and ALADIN gene was not clear. However, further evaluations might be needed to demonstrate clinical correlations with these data.

\section{References}

1. Park W, Vaezi MF. Etiology and pathogenesis of achalasia: the current understanding. Am J Gastroenterol 2005;100:1404-1414.

2. Scherb J, Arias IM. Achalasia of the esophagus and Chagas' disease. Gastroenterology 1962;43:212-215.

3. Storch WB, Eckardt VF, Wienbeck M, et al. Autoantibodies to Auerbach's plexus in achalasia. Cell Mol Biol (Noisy-le-grand) 1995;41:1033-1038.

4. Ruiz-de-León A, Mendoza J, Sevilla-Mantilla C, et al. Myenteric antiplexus antibodies and class II HLA in achalasia. Dig Dis Sci
2002;47:15-19.

5. Houlden H, Smith S, De Carvalho M, et al. Clinical and genetic characterization of families with triple A (Allgrove) syndrome. Brain 2002;125:2681-2690

6. Chávez M, Moreno C, Pérez A, et al. [Allgrove syndrome (achalasia-alacrima-adrenal gland insufficiency): report of a case.] Rev Gastroenterol Peru 1996;16:153-157. [Spanish]

7. Verma S, Brown S, Dakkak M, Bennett JR. Association of adult achalasia and alacrima. Dig Dis Sci 1999;44:876-878.

8. Brooks BP, Kleta R, Stuart C, et al. Genotypic heterogeneity and clinical phenotype in triple A syndrome: a review of the NIH experience 2000-2005. Clin Genet 2005;68:215-221.

9. Vitali C, Bombardieri S, Jonsson R, et al. Classification criteria for Sjogren's syndrome: a revised version of the European criteria proposed by the American-European Consensus Group. Ann Rheum Dis 2002;61:554-558.

10. Methodologies to diagnose and monitor dry eye disease: report of the Diagnostic Methodology Subcommittee of the International Dry Eye WorkShop (2007). Ocul Surf 2007;5:108-152.

11. Handschug K, Sperling S, Yoon SJ, Hennig S, Clark AJ, Huebner A. Triple A syndrome is caused by mutations in AAAS, a new WD-repeat protein gene. Hum Mol Genet 2001;10:283-290.

12. Tullio-Pelet A, Salomon R, Hadj-Rabia S, et al. Mutant WD-repeat protein in triple-A syndrome. Nat Genet 2000;26:332-335.

13. Weber A, Wienker TF, Jung M, et al. Linkage of the gene for the triple A syndrome to chromosome 12q13 near the type II keratin gene cluster. Hum Mol Genet 1996;5:2061-2066.

14. Stratakis CA, Lin JP, Pras E, Rennert OM, Bourdony CJ, Chan WY. Segregation of Allgrove (triple-A) syndrome in Puerto Rican kindreds with chromosome 12 (12q13) polymorphic markers. Proc Assoc Am Physicians 1997; 109:478-482.

15. Nakamura K, Yoshida K, Yoshinaga T, et al. Adult or late-onset triple A syndrome: case report and literature review. J Neurol Sci 2010;297:85-88. 